\title{
CYTOTOXICITY OF CRYPTOSULA ZAVJALOVENSIS KUBANIN EXTRACT AGAINST BREAST CANCER CELL LINE MCF7
}

\author{
LOVEILLE JUN AMARILLE GONZAGA ${ }^{1 *}$, ISABEL CAVACO ${ }^{2}$, and HELENA FORTUNATO ${ }^{3}$
}

${ }^{1}$ Department of Chemistry, College of Science and Mathematics, University of Southern Mindanao, Kabacan, Cotabato, 9407 Philippines

${ }^{2}$ Departamento de Quimica e Farmacia, Universidade do Algarve, Campus de Gambelas, 8005-139 Faro, Portugal

${ }^{3}$ Department of Natural History Sciences, Faculty of Science, Hokkaido University, N10 W8 Kita-ku, Sapporo 060-0810, Japan

\begin{abstract}
The marine environment is an abundant source of diverse biologically active compounds that demonstrate great potential applications in pharmaceutics and medicine. Although novel biologically active secondary metabolites can be potentially found in bryozoans, there have been a few studies on these organisms. Bryozoans are sessile colonial animals commonly found in great diversity in shallow waters. In this study, samples of the bryozoan Cryptosula zavjalovensis Kubanin were collected from Akkeshi, Japan, and were extracted using ethanol. The crude extract was separated using ethyl acetate (EtOAc) and water to obtain organic and aqueous fractions, respectively. In the 3-(4,5-dimethylthiazol-2-yl)-2,5-diphenyltetrazolium bromide (MTT) assay, the EtOAc fraction demonstrated cytotoxicity towards MCF7 breast cancer cells. The EtOAc extract was subsequently fractionated through solid-phase extraction using a gradient of methanol and water (E1 80:20 v/v and E2 100:0 v/v) and using methanol and chloroform (E3 50:50 v/v). Toxicity profiling revealed that the toxicity toward the human MCF7 breast cancer cells of the E2 and E3 fractions is comparable to that of cisplatin, indicating the excellent cytotoxic activity of the EtOAc fractions of $C$. zavjalovensis. Further studies are thus warranted to isolate the novel compounds in these fractions and determine their potential chemotherapeutic application.
\end{abstract}

Keywords: cytotoxicity, marine bryozoan, Cryptosula zavjalovensis, MCF7

The biodiversity in our oceans is a viable source of diverse natural products with various potential applications, particularly in pharmaceutics. The heightened interest in the marine environment has led to the discovery of a great number of new natural products. Recently, more than a thousand new compounds are being discovered and reported annually (1). These compounds demonstrate potential applications in pharmaceutics and medicine, particularly as anticancer agents.

While natural products are scarce in vertebrates (2), they have been obtained in abundance from other marine organisms, such as algae, sponges, cnidarians, bryozoans, mollusks, tunicates, echinoderms, marine microorganisms and phytoplankton, mangroves, and other intertidal plants and microorganisms. However, the efforts on marine natural product discovery have focused on microorganisms, and most of the new secondary metabolites recently obtained from the marine environment were isolated from this group (1). Marine microorganisms have been reported to display antibiotic, antifungal, and antiviral activities. However, although they are potential sources of novel natural products, a few studies have investigated the secondary metabolites in these organisms, particularly bryozoans.

Bryozoans are invertebrates that can be found both in freshwater and marine environments, particularly in shallow areas. Most of the known bryozoans are marine bryozoans; they are found in coastal waters where they are attached to rocks, pilings, shells, algae, and other animals. However, the taxonomic diversity of freshwater bryozoans is rather low (3), and records show that they have remained unchanged for the past ca. 480 million years (4).

Bryozoans are tiny, sessile, colonial animals that are often called moss animals. They have a distinguishing specialized feeding structure called a lophophore, which is either a horseshoe- or circular-shaped tentacle extension of the body wall that

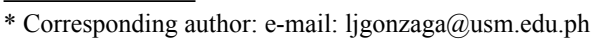


surrounds the mouth. The basic body plan of a bryozoan consists of a polyp protected by a gelatinous or calcareous enclosure called a zooid. Several zooids aggregate to form a colony. Bryozoan colonies can either be encrusting, wherein flat and delicate, lacy crusts are formed; arborescent, wherein colonies can be erect, branching, or tree-like; or free living. Due to these features, bryozoan colonies have often been mistaken for hydroids, corals, or seaweeds. While some bryozoan colonies encrust rocks, pilings, and algae, some are known to grow on the bottom of ships and result in fouling, causing drag and reducing efficiency and maneuverability.

Most of the metabolites isolated from bryozoans are alkaloids (5). Other secondary metabolites obtained from bryozoans are macrolide lactones, indole alkaloids, isoquinoline quinones, sterols, and other carbohydrates with a heteroatom, such as nitrophenols and disulfides (6).

In terms of chemical ecology, one of the most studied bryozoan species is Bugula neritina, from which bryostatins, a promising anticancer metabolite that shows significant biological activities, were isolated (7). Upon the isolation and the elucidation of the structure of bryostatin-1, there had been numerous studies exploring its anticancer and antitumor potential.

By contrast, one of the least studied genera of bryozoans is Cryptosula. Under this genus, only five species have been recorded. The first recorded species is Cryptosula pallasiana, which has a cosmopolitan distribution. The worldwide distribution of bryozoans, as with other fouling species, is suggested to have been facilitated by ships, and bryozoans may become invasive particularly in ports and harbors (8).

Similar to the other bryozoans in the genus Cryptosula, C. pallasiana is encrusting. Generally, C. pallasiana colonies are white, orange, or pink in color. Moreover, the aperture of $C$. pallasiana is often described as bell-shaped. This species has no spines, has no avicularia, which are jaw-like structures that open and close, and has no ovicells that brood embryos; all of these features are conspicuous in many bryozoans.

C. pallasiana is difficult to differentiate from C. zavjalovensis. Similarly, C. zavjalovensis colonies are encrusting and are orange in color. However, microscopic inspection has revealed that $C$. zavjalovensis exhibits a distinct zooid structure, and this distinct feature is even clearer under a scanning electron microscope.

Moreover, C. zavjalovensis emits a lemon-like odor, a characteristic that is hypothesized to be a defense mechanism against predators. This odor might be due to one of the many natural products from the species, some of which might be novel. It is therefore of interest to investigate $C$. zavjalovensis-derived natural products, which may demonstrate potential bioactivities.

Research on Cryptosula is considerably scarce, let alone the research on $C$. zavjalovensis, which is not as globally distributed as C. pallasiana. C. $z a-$ vjalovensis has been reported in areas in the North Pacific region, such as in Vladivostok in Russia, Alaska in the USA (9), and Hokkaido in Japan (10).

This study aimed to determine the biological activity of the C. zavjalovensis crude extract, particularly its cytotoxicity against the breast cancer cell line MCF7.

\section{EXPERIMENTAL}

\section{Sample collection}

Samples of C. zavjalovensis were collected at the Akkeshi Marine Station, Hokkaido, Japan during low tide, with tide heights of 0.2-0.4 m. The samples were collected from algae and rocks encrusted with bryozoan colonies. Algae encrusted with bryozoans were gathered, and bryozoan colonies in rocks were scraped; the collected samples were placed in containers containing seawater and then brought to the marine laboratory for separation. The bryozoan samples were delicately separated and removed from the algae and rocks by using forceps. Foreign particles in the samples were also removed. The bryozoan samples collected were inspected under a compound light microscope (Olympus) to examine their zooid structure and to isolate the $C$. zavjalovensis samples. The samples emitted a lemon-like odor, a characteristic distinct to this species. The samples were weighed and placed in vials filled with ethanol for transport to the laboratory for analysis. At the laboratory, the vials were kept in a freezer $\left(-15^{\circ} \mathrm{C}\right)$ until analysis.

\section{Solvent extraction}

The sample was homogenized by mashing using a mortar and pestle, filtered through vacuum filtration, washed with ethanol $(100 \mathrm{~mL})$ three times, and then dried in vacuo to obtain a crude extract (340 mg). The crude extract was partitioned into an organic and aqueous fraction using ethyl acetate $(100 \mathrm{~mL})$ and Milli- $\mathrm{Q}^{\circledR}$ water $(100 \mathrm{~mL})$, respectively. This procedure was performed three times to achieve a better separation of the two fractions. The organic and aqueous fractions were dried in vacuo to obtain an ethyl acetate (EtOAc) extract $(21.3 \mathrm{mg})$ and Milli- ${ }^{\circledR}$ water $\left(\mathrm{H}_{2} \mathrm{O}\right)$ extract $(300 \mathrm{mg})$, respectively. 


\section{Solid-phase extraction}

The EtOAc extract was fractionated by solidphase extraction using a Strata ${ }^{\circledR}$ SPE to obtain three fractions: E1 80:20 and E2 100:0 (methanol (MeOH): $\mathrm{H}_{2} \mathrm{O}, \mathrm{v} / \mathrm{v}$ ) and E3 50:50 (methanol: chloroform, v/v). The wash and elution volume used was $4 \mathrm{~mL}$. The extracts were dried in vacuo, weighed, and placed in pre-weighed vials prior to cytotoxicity sample preparation and storage.

\section{Reversed-phase chromatography}

The $\mathrm{H}_{2} \mathrm{O}$ extract was fractionated by reversedphase chromatography using octadecyl (C18) as a stationary phase with a gradient consisting of $\mathrm{MeOH}$ and $\mathrm{H}_{2} \mathrm{O}(\mathrm{v} / \mathrm{v})$ to obtain four fractions: H1 0:100, H2 30:70, H3 60:40, and H4 100:0. The wash and elution volume used was $6 \mathrm{~mL}$. The extracts were dried in vacuo, weighed, and placed in pre-weighed vials prior to cytotoxicity sample preparation and storage.

\section{Cytotoxicity testing}

Cytotoxicity against the human breast cancer cell line MCF7 (Culture Collections, Public Health England) was evaluated using MTT (3-(4,5-dimethyl-2-thiazolyl)-2,5-diphenyl-2H-tetrazolium bromide) assay. The MCF7 cell line was maintained in RPMI-1640 (Wako) with 10\% fetal bovine serum (FBS) (BioWest). The cells were seeded at a density of $1 \times 10^{4}$ cells per well in a 96 -well plate and then treated with different concentrations of the extracts after $24 \mathrm{~h}$ at $37^{\circ} \mathrm{C}$ and $5 \% \mathrm{CO}_{2}$. The cells were incubated for $72 \mathrm{~h}$ under the same conditions. The medium was removed and replaced with $100 \mu \mathrm{L}$ MTT in RPMI-1640 with $10 \%$ FBS $(0.5 \mathrm{mg} / \mathrm{mL})$. The MTT solution was aspirated after incubation for $3 \mathrm{~h}$ at $37^{\circ} \mathrm{C}$ and $5 \% \mathrm{CO}_{2}$. The formazan crystals that formed were dissolved in dimethyl sulfoxide (DMSO). It was incubated for $10 \mathrm{~min}$, and the optical density was measured at $570 \mathrm{~nm}$ using a Thermo Labsystems Multiskan JX plate reader.

\section{Statistical analysis}

The $\mathrm{IC}_{50}$ results from the MTT assay were reported as the mean of three independent experiments. One-way ANOVA was used to compare the positive control, cisplatin, and extracts. $\mathrm{P}<0.05$ indicated a significant difference.

\section{RESULTS AND DISCUSSION}

Despite their potential to demonstrate biological activities, Cryptosula species, particularly C. zavjalovensis, have been rarely investigated. This study evaluated the cytotoxic activity of $C$. zavjalovensis extracts against the human breast cancer cell line MCF7 using an MTT assay to screen for the presence of bioactive compounds.

The initial screening of the EtOAc and water fractions revealed the cytotoxic activity of the C. $z a$ vjalovensis crude extract against the MCF7 breast cancer cells. Figure 1 shows the $\mathrm{IC}_{50}$ values of the EtOAc and water extracts.

Cisplatin, a known chemotherapeutic drug, was used as a positive control in this study. Cisplatin has demonstrated anticancer activity against various types of tumors (11); moreover, it has already been used against breast cancer cells, and it is sometimes used in combination with other drugs because of its synergistic effects and because it can minimize cisplatin resistance (12). Moreover, cisplatin-related toxicities are dose-dependent (13), making it an ideal positive control. DMSO was used as the negative control.

Statistical analysis revealed that the $\mathrm{IC}_{50}$ values did not significantly differ between cisplatin and the EtOAc extract, but a significant difference was observed between cisplatin and the water extract. This result indicates that the cytotoxic activity of the EtOAc extract is comparable to that of cisplatin. Given the cytotoxicity of the EtOAc extract against the MCF7 breast cancer cells, it was fractionated into three fractions through solidphase extraction. Figure 2 shows the $\mathrm{IC}_{50}$ values of the three fractions.

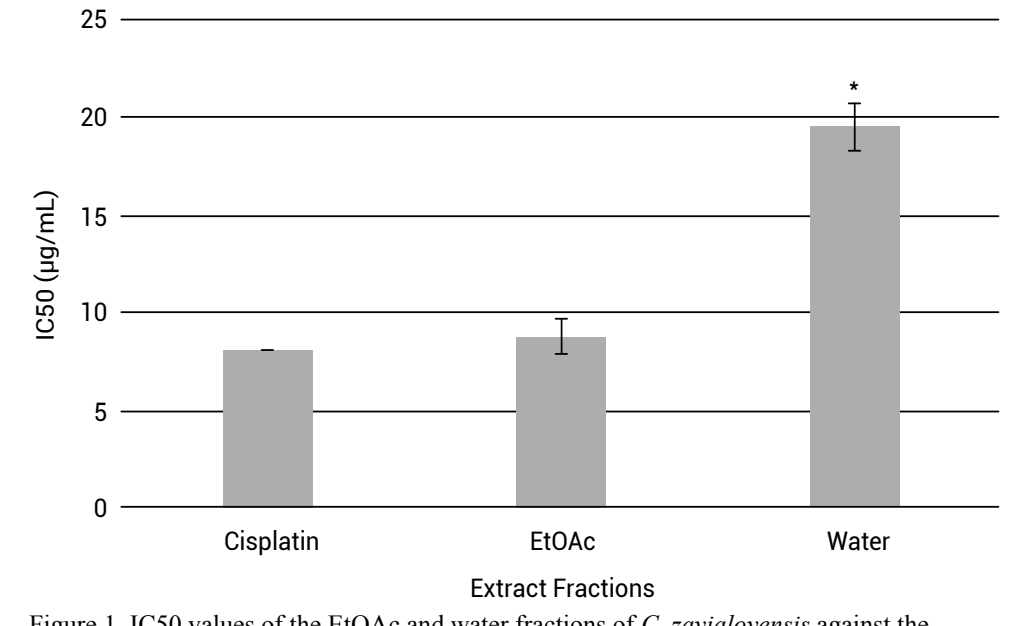

Figure 1. IC50 values of the EtOAc and water fractions of C. zavjalovensis against the human breast cancer cell line MCF7.

$*$ denotes significant difference with cisplatin $(\mathrm{p}<0.05)$. 
A significant difference in the $\mathrm{IC}_{50}$ values was observed between cisplatin and E1. By contrast, no significant difference in the $\mathrm{IC}_{50}$ values was observed between cisplatin and E2 as well as between cisplatin and E3. These findings indicate that the bioactive compounds in C. zavjalovensis, the cytotoxic activities of which are comparable to those of cisplatin, were present in E2 and E3.

Although the $\mathrm{H}_{2} \mathrm{O}$ extract was not as cytotoxic as cisplatin, it still exhibited mild cytotoxicity. The $\mathrm{H}_{2} \mathrm{O}$ extract was also subsequently fractionated using reversed-phase chromatography. Figure 3 shows the $\mathrm{IC}_{50}$ values of the four fractions of the $\mathrm{H}_{2} \mathrm{O}$ extract.

The $\mathrm{IC}_{50}$ values of cisplatin significantly differed from those of the $\mathrm{H}_{2} \mathrm{O}$ fractions ( $\left.\mathrm{H1}-4\right)$, indicating that the $\mathrm{H}_{2} \mathrm{O}$ fractions are not as cytotoxic as cisplatin. Nevertheless, these fractions still exhibited mild toxicity against the MCF7 breast cancer cells.

The cytotoxic activity of the EtOAc fractions (E2 and E3) is possibly due to the phytochemicals present in the $C$. zavjalovensis extract. Moreover, the cytotoxicity test results for the EtOAc and $\mathrm{H}_{2} \mathrm{O}$ fractions indicate the presence of bioactive compounds that exhibit mild to strong cytotoxicity against the MCF7 human breast cancer cells. However, the compounds present in $C$. zavjalovensis have not yet been studied. Unlike the compounds found in C. pallasiana, a bryozoan species that has been extensively studied due to its global distribution, the compounds present in C. zavjalovensis are rarely investigated due to the restricted distribution of this species.

Natural products in Cryptosula were isolated and identified only recently. Thirteen sterols, six of which are new, were isolated from the carbon tetrachloride extract of $C$. pallasiana. Initially, it was reported that four of these sterols are synthetic, but their isolation from $C$. pallasiana proves that they are natural sterols. Seven of these isolates exhibited moderate cytotoxicity against the human myeloid leukemia cell line HL-60 (14).

Furthermore, three aromatic compounds ( $p$-methylsulfonylmethyl-phenol, $p$ hydroxybenzaldehyde, and methylparaben), nine alkaloids (7-bromoquinolin-4(1H)-one, 7-bromo-2,4(1H,3H)-quinazolinedione, benzamide, phenylacetamide, 4(3H)-quinazolinone, thymine, uracil, hypoxanthin, and tryptophan), and two glycerol derivatives (glycerol and monoheneicosanoin) were further isolated from $C$. pallasiana. Two of the isolates, $p$-methylsulfonylmethyl-phenol and 7-bromoquinolin-4(1H)-one, were novel natural products. These two isolates, together with another isolate (7-bromo-2,4(1H,3H)quinazolinedione), were evaluated for their cytotoxic activity against the human myeloid leukemia cell line HL-60. Of the three, only 7-bromo-2,4(1H,3H)quinazolinedione showed cytotoxic activity, whereas the two other isolates were inactive (15).

In addition, four ceramides, four sterols, and a lactone were isolated; of these isolates, one sterol and two ceramides were novel natural products. The novel sterol
Figure 3. IC50 values of the $\mathrm{H}_{2} \mathrm{O}$ fractions, namely, $\mathrm{H} 10: 100, \mathrm{H} 230: 70, \mathrm{H} 360: 40$ $\mathrm{H} 4100: 0$ (methanol: $\mathrm{H}_{2} \mathrm{O}, \mathrm{v} / \mathrm{v}$ ) against the human breast cancer cell line MCF7. *denotes significant difference with cisplatin $(\mathrm{p}<0.05)$. 
was (23R)-methoxycholest-5,24-dien-3 $\beta$-ol, and the two new ceramides were $(2 \mathrm{~S}, 3 \mathrm{R}, 4 \mathrm{E}, 8 \mathrm{E})-2-$ (tetradecanoylamino)-4,8-octadecadien-1,3-diol and (2S,3R,20R,4E, 8E)-2-(tetradecanoylamino)-4,8octadecadien-1,3,2'-triol. Loliolide, a lactone, exhibited strong cytotoxicity against the human myeloid leukemia cell line HL-60, against the human liver cancer cell line Hep G2, and against the human gastric cancer cell line SGC-7901. The new sterol, (23R)methoxycholest-5,24-dien-3 $\beta$-ol, exhibited moderate cytotoxicity against these three cell lines (16).

Within the Phylum Bryozoa, only three orders have been reported to contain natural products and display biological activity (17). One of these orders where bioactive secondary metabolites have been found is Cheilostomata, where C. zavjalovensis belongs. This order also includes $B$. neritina, from which bryostatins were isolated. The majority of the natural products isolated from other cheilostomes were alkaloids. For instance, flustramine A and B (18), flustramine C, flustraminol A and B (19), flustramide A (20), and dihydroflustramine C (21) were isolated from Flustra foliacea. In addition, pterocellin A and B (22), with pterocellin A exhibiting a potent antitumor activity toward a murine leukemia cell line (23), pterocellins C-F (24), and 5-bromo8 -methoxy-1-methyl- $\beta$-carboline (25) were isolated from Pterocella vesiculosa.

It was also observed that the same species of bryozoans may produce different natural products. This was the case with $B$. neritina, wherein different populations produced different bryostatins (26). Moreover, it is possible that the natural products found in some species of bryozoans may be produced by a bacterial symbiont. Bryostatins have been found to be produced by Endobugula sertula, a unique bacterial symbiont of $B$. neritina, to protect the larvae of $B$. neritina against fish predation (27).

A preliminary liquid chromatography-mass spectrometry (LC-MS) profiling of the EtOAc extract of $C$. zavjalovensis was performed both in positive and negative ionization modes to separate its many constituents. The results revealed promising peaks for the EtOAc fractions. A search in the MarinLit ${ }^{\circledR}$ database using these preliminary mass spectrometry data was performed, and no matches were found, suggesting that the obtained products are novel compounds.

Given the numerous natural products found in other cheilostomes and given the extent of C. $z a v$ jalovensis distribution, an investigation on the presence of biologically active natural products, some of which are possibly novel, is warranted. Moreover, the results of the cytotoxicity tests underscore the need for further research to isolate and identify the bioactive compounds present in C. zavjalovensis and to evaluate their potential chemotherapeutic use.

\section{CONCLUSION}

The compounds extracted from C. zavjalovensis are bioactive. Cytotoxicity screening showed that the bioactive compounds contained in the organic EtOAc extract, specifically in the E2 and E3 fractions, displayed $\mathrm{IC}_{50}$ values that are comparable to those of cisplatin. The water fractions also exhibited mild cytotoxicity.

These results warrant further analysis of the extract owing to its multiple bioactivities and its anticancer potential. In order to better understand the bioactivity and cytotoxicity of these extracts, it is suggested that these compounds be isolated and identified. This endeavor will require structure elucidation of the bioactive compounds. Moreover, it is recommended that the extract be tested on other cancer cell lines.

\section{Conflict of interest}

The authors declare no conflicts of interest.

\section{REFERENCES}

1. Blunt J.W., Copp B.R., Keyzers R.A., Munro M. H., Prinsep M.R.: Nat. Prod. Rep. 33, 382 (2016).

2. Jha R.K., Zi-rong X.: Mar. Drugs 2, 123 (2004).

3. Hayward P., Ryland J.: Cyclostome Bryozoans: Keys and notes for the identification of the species, The Linnean Society of London and The Estuarine and Brackish-Water Sciences Association, London 1985.

4. Fortunato H.: Reg. Stud. Mar. Sci. 2, 32 (2015).

5. Blunt J.W., Copp B.R., Munro M.H., Northcote P., Prinsep M.R.: Nat. Prod. Rep. 21, 1 (2004).

6. Sinko J., Rajchard J., Balounova Z., Fikotova L.: Vet. Med. (Praha) 57, 177 (2012).

7. Pettit G.R., Herald C.L., Doubek D.L., Herald D.L.: J. Am. Chem. Soc. 104, 6846 (1982).

8. Almeida A.C., Souza F.B., Gordon D.P., Vieira L.M.: Zoologia 32, 476 (2015).

9. Dick M.H., Grischenko A.V., Mawatari S.F.: J. Nat. Hist. 39, 3687 (2005).

10. Grischenko A.V., Dick M.H., Mawatari S.F.: J. Nat. Hist. 41, 1047 (2007).

11. Dasari S., Tchounwou P.: Eur. J. Pharmacol. 740, 364 (2014).

12. Prabhakaran P., Hassiotou F., Blancafort P., Filgueira L.: Front. Oncol. 3, 1 (2013). 
13. Florea A.-M., Büsselberg D.: Cancers 3, 1351 (2011).

14. Tian X.-R., Tang H.-F., Li Y.-S., Lin H.-W., Chen X.-L., et al.: Mar. Drugs 9, 162 (2011).

15. Tian X.-R., Tang H.-F., Li Y.-S., Lin H.-W., Zhang X.-Y., et al.: Rec. Nat. Prod. 9, 628 (2014).

16. Tian X.-R., Gao Y.-Q., Tian X.-L., Li J., Tang H.-F., et al.: Mar. Drugs 15, 120 (2017).

17. Sharp J.H., Winson M.K., Porter J.S.: Nat. Prod. Rep. 24, 659 (2007).

18. Carle J.S., Christophersen C.: J. Org. Chem. 45, 1586 (1980).

19. Carle J.S., Christophersen C.: J. Org. Chem. 46, 3440 (1981).
20. Wulff P., Carle J., Christophersen C.: Comp. Biochem. Physiol. B Biochem. Mol. Biol. 71, 523 (1982).

21. Wright J.: J. Nat. Prod. 47, 893 (1984).

22. Yao B., Prinsep M.R., Nicholson B.K., Gordon D.P.: J. Nat. Prod. 66, 1074 (2003).

23. Wang A.T., Prinsep M.R., Martinus R.D.: Springerplus 5, 1 (2016).

24. Prinsep M.R.: J. Nat. Prod. 71, 134 (2008).

25. Till M., Prinsep M.R.: J. Nat. Prod. 72, 796 (2009).

26. Davidson S.K., Haygood M.G.: Biol. Bull. 196, 273 (1999).

27. Lopanik N., Lindquist N., Targett N.: Oecologia 139, 131 (2004). 